\title{
Breast Pump Usage is a Safe and Efficacious Method of Labor Induction for Women with Risk Factors for Uterine Rupture
}

\author{
Jonathan Orrelle ${ }^{1}$ and Jacob Bornstein ${ }^{2 *}$ \\ ${ }^{1}$ Azrieli Faculty of Medicine, Bar-Ilan University Faculty of Medicine, Israel \\ ${ }^{2}$ Department of Obstetrics \& Gynecology, Galilee Medical Center, Israel \\ *Corresponding author: Jacob Bornstein, Department of Obstetrics \& Gynecology, Galilee Medical Center, Israel
}

\section{ARTICLE INFO}

Received: 业 December 15, 2020

Published: 幽 December 23, 2020

Citation: Jonathan Orrelle, Jacob Bornstein. Breast Pump Usage is a Safe and Efficacious Method of Labor Induction for Women with Risk Factors for Uterine Rupture. Biomed J Sci \& Tech Res 32(5)2020. BJSTR. MS.ID.005314.

Keywords: Labor Induction; Breast Pump, Nipple Stimulation; Oxytocin; High Risk Pregnancy

Abbreviations: CST: Contraction Stress Test; GM: Grand Multiparas; IRB: Institutional Review Board

\section{ABSTRACT}

Objective: Labor induction accounts for approximately $22 \%$ of live births. There is a demand for safe methods that do not increase the risk of uterine rupture. This is especially true for women attempting vaginal birth after cesarean section and for women with grand multiparity. Nipple stimulation is a convenient, inexpensive, and noninvasive method for inducing labor. Our aim was to evaluate the efficacy of a modified method breast-pump application, among pregnant women with risk factors for uterine rupture.

Patients and Methods: A retrospective analysis of breast pump usage in 231 pregnant women with risk factors for uterine rupture.

Result: Of the 231 women, 101 were Grand Multiparas (GM) (44\%), and 130 had at least one prior C-section (56\%). 147 (64\%) of women delivered vaginally, and 84 (36\%) underwent C-section. The percentage of vaginal births within 24 hours (defined as "success") was similar among women with GM (56.4\%) and those undergoing C-section (48.4\%). No significant complications were observed. The GM group and the C-section group differed with regards to maternal age (35.57 vs. 31.38, respectively; $\mathrm{p}<0.05$ ), number of past pregnancies and births (6.76 and 5.70 vs. 2.45 and 1.98 , respectively; $\mathrm{p}<0.05$ ), and the increase in Bishop's score before and after induction (3.02 vs. 2.54, respectively; $\mathrm{p}=0.04$ ).

Conclusion: Breast pump stimulation is an effective method to induce labor in pregnant women with risk factors for uterine rupture.

\section{Introduction}

Nipple stimulation has been documented as a method of birth induction and cervical ripening in many cultures [1,2] and European medical documents from the $18^{\text {th }}$ and $19^{\text {th }}$ centuries indicate that the method was used in cases of prolonged birth [3]. Uterine contractions formed through nipple stimulation are also used for Contraction Stress Test (CST) [4] that is performed in late pregnancy to examine the fetal heart rate response to uterine contractions. Two major advantages of nipple stimulation are its low cost and high safety profile [5,6].

One hypothesis for the mechanism by which nipple stimulation leads to uterine contractions is that the mechanical stimulation of the nipple mimics the infant's sucking action, which results in the production and secretion of endogenous oxytocin from the pituitary gland in both pregnant and non-pregnant women [1,2]. Oxytocin then binds to oxytocin receptors found in the membranes of uterine muscle cells. When bound to its receptor, oxytocin activates the phospholipase $\mathrm{C}$-inositol pathway $[2,7,8]$ which causes an increase in intracellular calcium levels and eventually leads to a synchronous contraction of the uterine muscle. The number of oxytocin receptors increases 100 - to 300 -fold during pregnancy 9 . However, no direct relationship has been clearly demonstrated between blood oxytocin levels and uterine activity response during breast stimulation $[2,9]$. 
Among pregnant, uniparous, or multiparous women with no risk factors, inducing and augmenting birth via nipple stimulation is used10. According to previous studies, nipple stimulation of 30 to 60 minutes will start contractions in $50 \%$ of women [10]. Nipple stimulation has been found to reduce the number of cases of prolonged birth ( $>72$ hours) and postpartum hemorrhage [11]. Nipple stimulation as a means of labor induction gives women greater control over the process and has the advantage of being a natural and cost-free method. Because this is an indirect method that is subject to physiologic feedback in which endogenous oxytocin is excreted from the pituitary gland, as compared to the direct intravenous administration of Pitocin, we believe that the resulting uterine contractions are not as intense as those caused by Pitocin. Therefore, it may be appropriate for use in women at risk of uterine rupture, such as those with a previous cesarean section, grand multiparity, twin pregnancy, and polyhydramnios, among other conditions. According to a Cochrane review, most of the information available in the literature regarding nipple stimulation is based on pregnant women in their third trimester who are not at risk of uterine rupture. Their conclusion is that further studies are needed to demonstrate the efficacy and safety of this method in pregnant women with risk factors for uterine rupture [11,12].

For several years, the labor ward at Galilee Medical Center has used a variant of nipple stimulation called "breast stimulation" that uses a breast pump. This method avoids direct contact with the nipple [13]. Using a breast pump for inducing labor has a number of advantages. The breast pump is inexpensive and can be reused many times (with sterilization between patients). It does not cause nipple pain, and in addition, the breast pump best mimics the sucking action of an infant, which ensures a consistent means of stimulation across patients. There is little information in the literature regarding inducing labor using a breast pump. In addition, the published studies deal mostly with births in women at low risk for uterine rupture. The present study aimed to evaluate the effectiveness of the breast pump method in pregnant women with risk factors for uterine rupture during delivery.

\section{Material and Methods}

We compared two cohorts of pregnant women at risk for uterine rupture: grand-multiparous women (with five or more vaginal births in the past) and women with a prior C-section. The maternity admission records of women who underwent induction of labor using breast pumps were reviewed. All women were hospitalized at the Galilee Medical Center between January 1, 2010 and June 30, 2014. During these years there were 5540 deliveries per year, the induction rate being $20 \%$. The main induction methods for women with low Bishop score were insertion of balloon catheter and intravaginal dinoprostone insertion, with a success rate of $80 \%$. The caesarean section rate during these years was stable $-23 \%$. For calculation of the sample size we estimated that there would be a $40 \%$ success rate among women with a prior C-section and a $60 \%$ success rate among grand-multiparous women. Success was defined as a normal vaginal birth after 24 hours.

\section{Study Design}

We conducted a retrospective observational study and reviewed hospital admission records of women who gave birth at the Galilee Medical Center. The IRB (Helsinki Committee) of the Galilee Medical Center approved the study on January 1, 2010, authorization number 64810. As a retrospective medical records review, we obtained a waiver of informed consent. The induction of these women was carried out in hospital, and breast pump was used for six hours or until labour developed.

\section{Study Population}

Inclusion criteria consisted of women who had undergone one prior cesarean and grand multiparous women who previously had 5 or more vaginal births. Exclusion criteria included pregnant women with one of the following contraindications for labor induction:

1) Placenta previa,

2) Transverse fetal lie,

3) Umbilical cord presentation,

4) Past cesarean delivery with classic or T-incision,

5) Previous uterine rupture,

6) Cervical carcinoma, or

7) Active genital herpes.

\section{Variables}

The dependent variable in the model was success, defined as a successful vaginal birth within 24 hours of initiating induction by breast stimulation. The primary outcomes were type of delivery within 24 hours of induction and cesarean section.

\section{Sample Size Calculation}

We calculated sample size based on a comparison of Labor success between the groups. We expected that as $60 \%$ patients out of the grand-multiparous women group and 75\% in prior C-section group (as 15\% differences between the groups). Based on 2-sided Chi square test, 150 patients in each group, we will achieve power of $80 \%$. Based on 1-sided hypothesis, 115 patients in each group is revealed a power of $79 \%$ and 118 releveled power of $80 \%$. Sample size was evaluated with the SamplePower software, release 3.0

\section{Statistical Methods}

Ordinal data were compared between the groups with MannWhitney test and qualitative data with Chi square test of Fisher's exact test (if expectancy<5). Alpha less than $5 \%$ was considered as significant result. The analysis was examined by IBM SPSS Statistics, version 25 . 


\section{Results}

The study was approved by the Institutional Review Board (IRB) of the Galilee Medical Center (Helsinki Committee) on January 1, 2010, approval number 64810. Of the 231 women included in the study, 101 were grand multipara (44\%), while 130 had a previous cesarean section (56\%). In the present study, 147 (64\%) of pregnancies ended in a vaginal delivery, and the remaining 84 ended in a cesarean section (36\%). Figure 1 shows the distribution of pregnant women by group before the current birth (grand multipara or previous C-section). It should be noted that out of the 130 women who delivered via cesarean section, 32 (24.6\%) underwent surgery for reasons not due to failure of induction with a breast pump (e.g., fetal stress, maternal request).

Figure 1 describes the cohorts of the study. The success rate, i.e. pregnancy ending with vaginal birth was 59.4\% (60/101) among
Grand Multiparas (GM) and 51.5\% (67/130) among women who had a previous $\mathrm{C}$-section. When restricted to women who delivered via $\mathrm{C}$-section for reasons not related to failure of induction using the breast pump, we documented a success rate of $67 \%$ and $61 \%$, respectively. As predicted, the average age of GM was significantly higher than that of women with a prior cesarean section (35.57 vs. 31.38 years; $\mathrm{p}<0.05)$. In addition, the numbers of past pregnancies and births were higher among the multiparous women compared to those who had a C-section (6.76 and 5.70 vs. 2.45 and 1.98, respectively; $\mathrm{p}<0.05)$. No differences were found between the two groups in the number of preterm, term, and post-term babies. There was a higher percentage of vaginal births among the GM population, and a higher percentage of caesarean sections among the C-section population of women. However, there was no statistically significant difference in the present birth outcome between the two study populations $(\mathrm{p}=0.130)$ (Tables 1 \& 2).

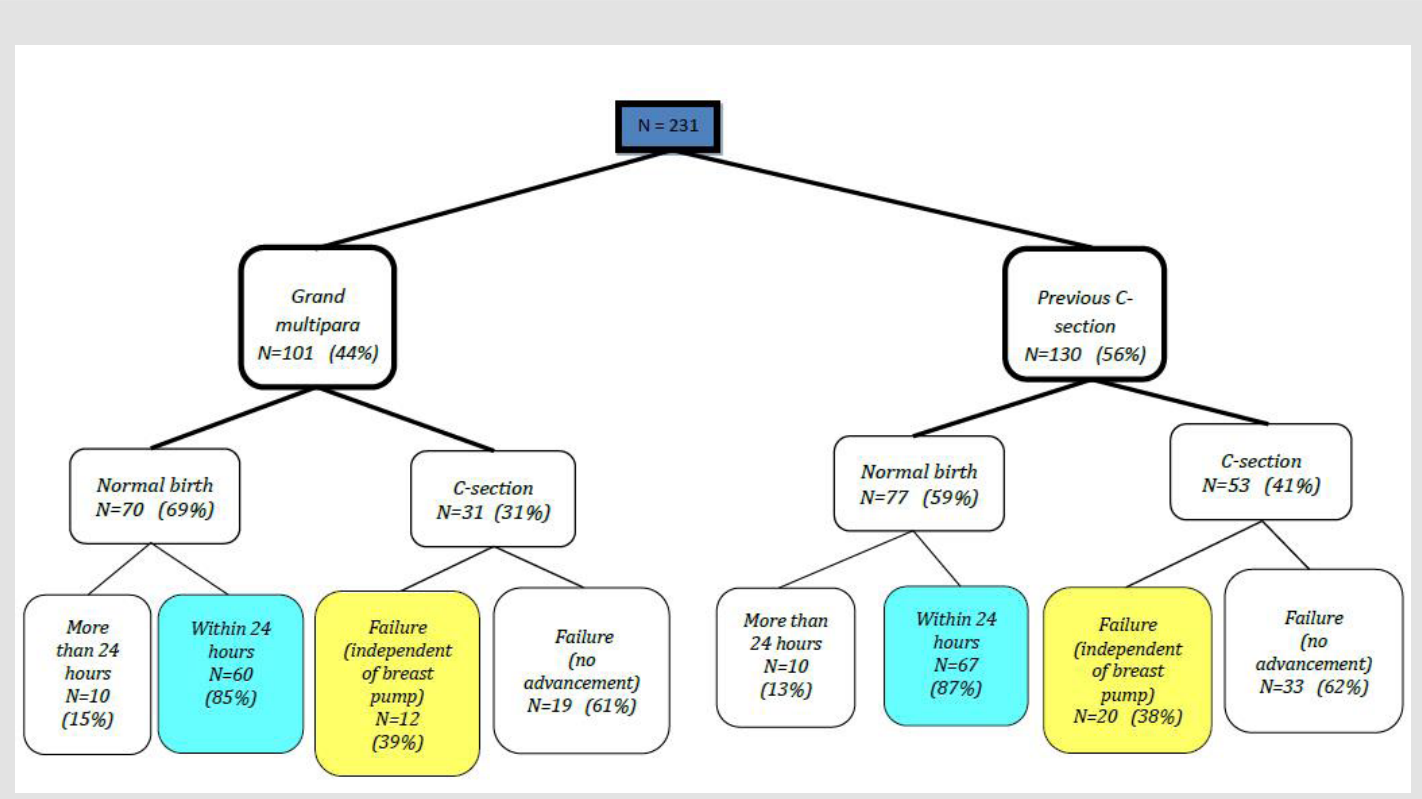

Figure 1: Study flowchart.

Table 1: Demographic and medical characteristics.

\begin{tabular}{|c|c|c|}
\hline & Prior Cesarean (N=130) & Multiparous women (N=101) \\
\hline $\begin{array}{c}\text { Years of age, mean (st) } \\
\text { Years of age, median (range) }\end{array}$ & $31.38(5.07)$ & $35.57(4.11)$ \\
$36(26-44)$ \\
\hline $\begin{array}{c}\text { Gravidity (Pregnancy number), median } \\
\text { (range) }\end{array}$ & $2(1-10)$ & $7(5-13)$ \\
\hline $\begin{array}{c}\text { Parity (Number of prior births), median } \\
\text { (range) }\end{array}$ & $1(1-7)$ & $5(4-10)$ \\
\hline $\begin{array}{c}\text { Current pregnancy: Number of preterm } \\
\text { deliveries (\%) }\end{array}$ & $8(6.2 \%)$ & $9(8.9 \%)$ \\
\hline $\begin{array}{c}\text { Current pregnancy: Number of term } \\
\text { pregnancy (\%) }\end{array}$ & $107(82.3 \%)$ & $75(74.3 \%)$ \\
\hline $\begin{array}{c}\text { Current pregnancy: Number of post-term }(\%) \\
\text { Median number of months since prior } \\
\text { caesarean section. median (range) }\end{array}$ & $15(11.5 \%)$ & $17(16.8 \%)$ \\
\hline
\end{tabular}


Note: *Independent sample t-test

**Wilcoxon rank sum test

****Mann-Whitney 2-sided

Table 2: Delivery mode.

\begin{tabular}{|c|c|c|c|c|}
\hline Delivery mode Study group & Cesarean section & Vaginal delivery & Total & Significance (p value, 2-sided test) \\
\hline Prior Cesarean group (\% of 130 women) & $53(40.8 \%)$ & $77(59.2 \%)$ & $130(100 \%)$ & \multirow{2}{*}{$0.13^{*}$} \\
\cline { 1 - 3 } Multiparous women group (\% of 101 women) & $31(30.7 \%)$ & $70(69.3 \%)$ & $101(100 \%)$ & \\
\cline { 1 - 3 } Total & $84(36 \%)$ & $147(64 \%)$ & $231(100 \%)$ & \\
\hline
\end{tabular}

Note: ${ }^{*} \mathrm{X}^{2}$ test

Reasons for labor induction are shown in Figure 2. There were no statistically significant differences in the distribution of these causes between the two populations, and therefore the reason for induction is not a factor affecting the present birth outcomes. There were also no differences in the number of inductions between the two groups, showing that this had no effect on the number of vaginal births in either group. In both groups, membrane rupturing was more frequently used after breast-pump suction than Pitocin as a means of inducing birth. There is an indirect relationship between the use of membrane rupturing and the success of inducing labor (vaginal birth within 24 hours) such that membrane rupturing increases the chance of a vaginal birth within 24 hours. Statistically, there was no significant difference (chi-square tests, $\mathrm{P}=0.182$ ) between the groups in the use of membrane rupturing and Pitocin after using a breast pump (Figures $3 \& 4$ ).

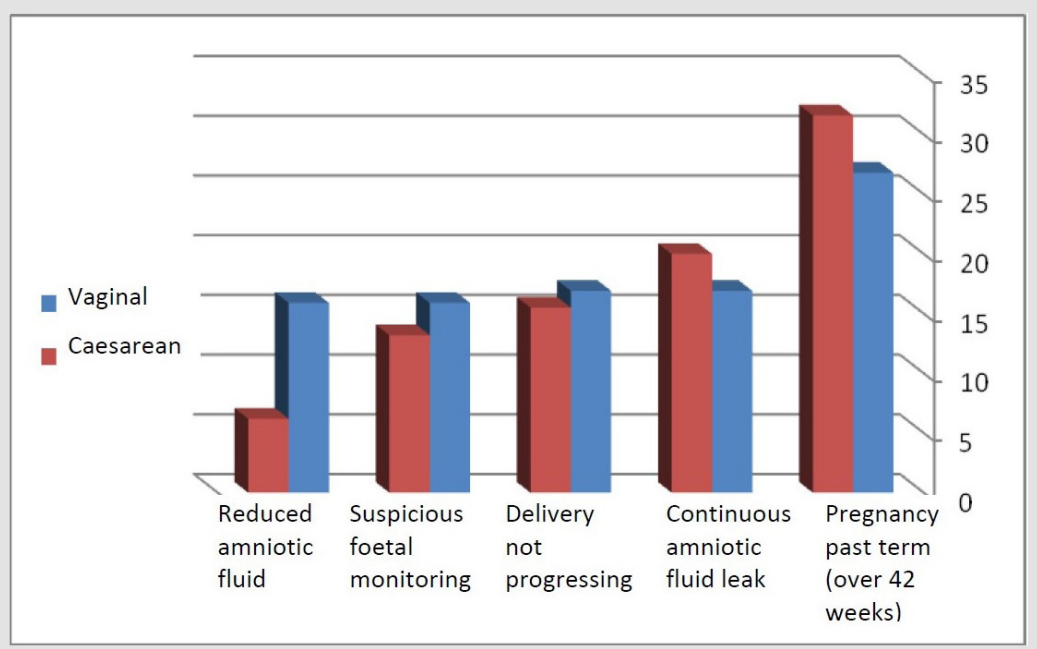

Figure 2: Principal causes for induced labor.

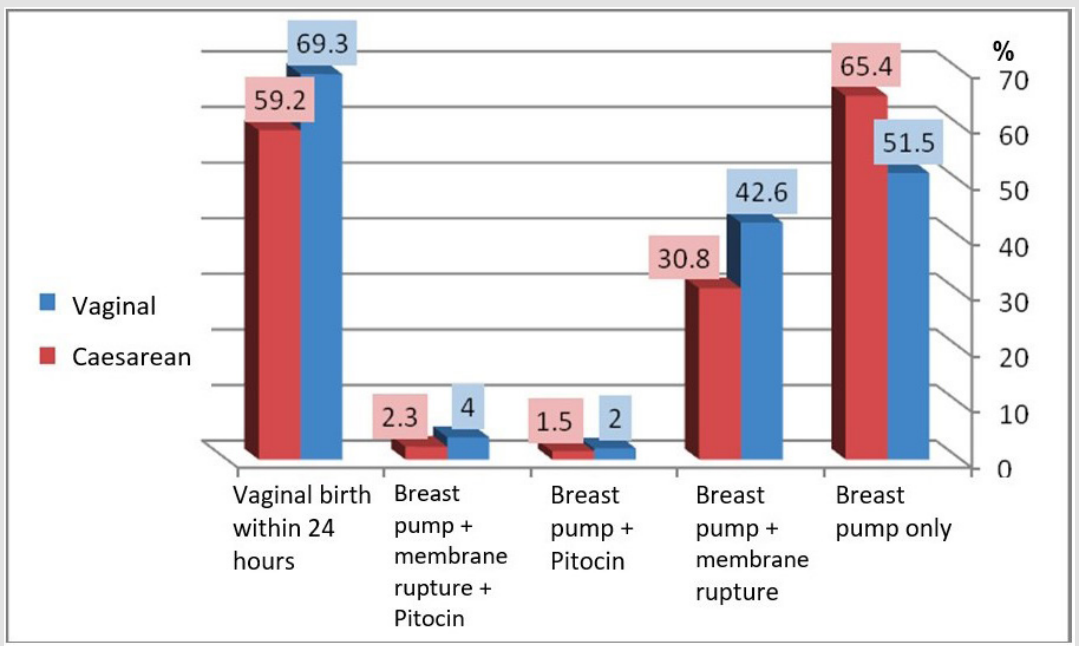

Figure 3: Types of labor induction other than breast pumps used in study deliveries. 


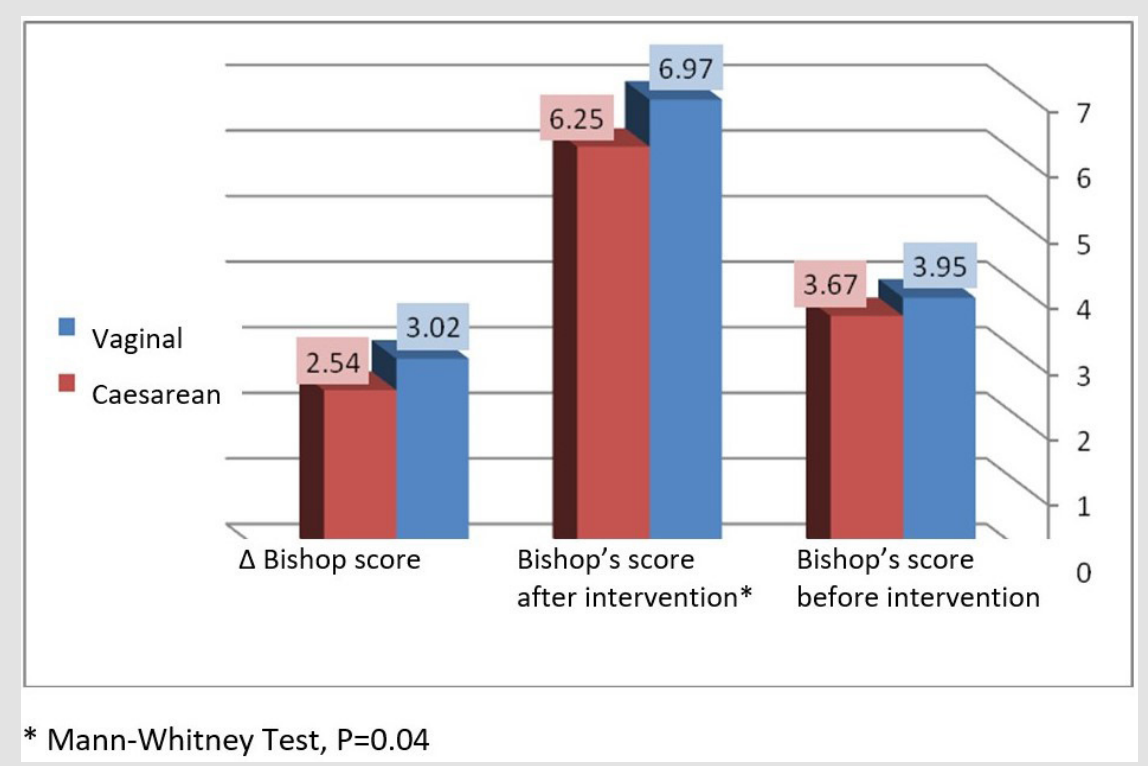

Figure 4: Bishop's values before and after intervention with the breast pump.

Due to the many variables, the different times they were given, and the necessary transition to epidural or spinal prior to caesarean section, it was difficult to establish a relationship between the type of analgesia and birth success. Avoiding either spinal or epidural analgesia (which diminish the sense of contractions and may decrease pushing efficacy) may result in higher vaginal birth rates. There was no cases of maternity mortality, rupture of the uterus, post-partum hemmorhage, hysterectomy or transfer to the intensive care unit. There was a significantly greater increase in Bishop's score $(\Delta)$ after using the breast pump among GM compared to women who in large part have never given birth vaginally.

\section{Discussion}

In the present study, we found that breast stimulation using a breast pump is an effective and safe method of inducing childbirth in pregnant women with risk factors for uterine rupture. We found that $59.4 \%$ of $\mathrm{GM}$ and $51.5 \%$ of women with a previous cesarean delivery had a successful vaginal birth within 24 hours of stimulation. The reasons for inducing labor, the number of times that the women underwent induction, and the rate of vaginal delivery were similar between the two groups. In our work, we retrospectively reviewed the inpatient records of 231 women, including 101 GM and 130 women who previously had cesarean deliveries. While the GM group had higher parity by definition (five or more births), the gestational age was similar between the groups. We also found a concordance between membrane rupture after breast pump stimulation and the success rate of vaginal birth within 24 hours. We demonstrated that this type of stimulation was more successful in women with a prior vaginal delivery compared to women with no prior vaginal delivery. While the two groups were similar in a number of ways, differences in baseline characteristics may have been partly due to differences in age, parity, or gravidity, or to other factors such as an increase in the Bishop's score or types of analgesic given during birth.

Breast stimulation using a breast pump for inducing labor and delivery has been studied to the best of our knowledge only twice in the last 32 years10, once in 1990 by Stein [14] and again in 1999 by Curtis [15]. These studied included a small sample and differed in terms of pregnancy duration, number of births, and different techniques used for performing nipple or breast stimulation, and they lacked a clear definition of the method's success. A safe method of labor induction is needed to enable safe vaginal birth after cesarean delivery and among GM. In the present study, we demonstrated that breast stimulation using a breast pump is an effective method of inducing childbirth in women with risk factors for uterine rupture. The number of cases reviewed in this paper is insufficient to determine the overall safety of the method, but significant complications were not observed in this study. A larger research population is warranted to shed additional light on the safety of the method and to further establish the safety of the breast pump for labor induction in high-risk groups.

\section{Conclusion}

Breast stimulation using a breast pump is an effective and safe method of inducing childbirth in pregnant women with risk factors for uterine rupture.

\section{Acknowledgement}

The authors thank Professor Ella Ophir for her contribution to the project and Mrs. Orly Yakir for assistance with the statistical analysis. 


\section{Conflict of Interests}

Competing interests: The authors declare that they have no competing interests.

Funding: This study was not funded

\section{Ethics Approval and Consent to Participate}

The IRB (Helsinki Committee) of the Galilee Medical Center approved the study on January 1, 2010, authorization number 64810. As a retrospective medical records review, we obtained a waiver of informed consent.

\section{Authors' Contributions}

JO collected the data, analyzed and interpreted the patient data, read and approved the final manuscript.

JB contributed to the concept of the study, analyzed and interpreted the patient data, was a major contributor in writing the manuscript, read and approved the final manuscript.

\section{References}

1. Riskin A (2017) Meeting the nutritional needs of premature babies: their future is in our hands. Br J Hosp Med (Lond) 78(12): 690-694.

2. Modi N, Bétrémieux P, Midgley J, Hartnoll G (2000) Postnatal weight loss and contraction of the extracellular compartment is triggered by atrial natriuretic peptide. Early Hum Dev 59(3): 201-208.

3. Rochow N, Raja P, Liu K, Fenton T, Landau Crangle E, et al. (2016) Physiological adjustment to postnatal growth trajectories in healthy preterm infants. Pediatr Res 79(6): 870-879.

4. Hiltunen H, Löyttyniemi E, Isolauri E, Rautava S (2018) Early Nutrition and Growth until the Corrected Age of 2 Years in Extremely Preterm Infants. Neonatology 113(2): 100-107.

5. Bhushan V, Paneth N (1991) The reliability of neonatal head circumference measurement. J Clin Epidemiol 44(10): 1027-1035.

6. Miller M, Vaidya R, Rastogi D, Bhutada A, Rastogi S (2014) From parenteral to enteral nutrition: a nutrition-based approach for evaluating postnatal growth failure in preterm infants. JPEN J Parenter Enteral Nutr 38(4): 489-497.

7. Abiramalatha T, Thomas N, Gupta V, Viswanathan A, Mc Guire W (2017) High versus standard volume enteral feeds to promote growth in preterm or low birth weight infants. Cochrane Database Syst Rev 9(9): CD012413.

8. Thomas N, Cherian A, Santhanam S, Jana AK (2012) A randomized control trial comparing two enteral feeding volumes in very low birth weight babies. J Trop Pediatr 58(1): 55-58.

9. Kuschel CA, Evans N, Askie L, Bredemeyer S, Nash J, et al. (2000) A randomized trial of enteral feeding volumes in infants born before 30 weeks' gestation. J Paediatr Child Health 36(6): 581-586.

10. Travers C, Ambalavanan N, Carlo W, Wang T, Salas AA, et al. (2019) Higher of usual Volume Feeds in Very Preterm Infants: A Randomize Control Trial. In Birgminghham UoAa (Eds.) Pediatric Academic Societies (PAS); Baltimore, Marynald, USA.

11. Alyahya W, Simpson J, Garcia AL, Mactier H, Edwards CA (2020) Early versus Delayed Fortification of Human Milk in Preterm Infants: A Systematic Review. Neonatology 117(1): 24-32.

12. Wu X, Jackson RT, Khan SA, Ahuja J, Pehrsson PR (2018) Human Milk Nutrient Composition in the United States: Current Knowledge,
Challenges, and Research Needs. Current Developments in Nutrition 2(7).

13. Belfort MB, Rifas Shiman SL, Sullivan T, Collins CT, Mc Phee AJ, et al. (2011) Infant growth before and after term: effects on neurodevelopment in preterm infants. Pediatrics 128(4): e899-906.

14. Sammallahti S, Pyhälä R, Lahti M, Lahti J, Pesonen AK, et al. (2014) Infant growth after preterm birth and neurocognitive abilities in young adulthood. J Pediatr 165(6): 1109-1115e3.

15. Neubauer V, Griesmaier E, Pehböck Walser N, Pupp Peglow U, Kiechl Kohlendorfer U (2013) Poor postnatal head growth in very preterm infants is associated with impaired neurodevelopment outcome. Acta Paediatr 102(9): 883-888.

16. Power VA, Spittle AJ, Lee KJ, Anderson PJ, Thompson DK, et al. (2019) Nutrition, Growth, Brain Volume, and Neurodevelopment in Very Preterm Children. J Pediatr 215: 50-55e3.

17. Tan MJ, Cooke RW (2008) Improving head growth in very preterm infants--a randomised controlled trial I: neonatal outcomes. Arch Dis Child Fetal Neonatal Ed 93(5): F337-341.

18. Van de Pol C, Allegaert K (2020) Growth patterns and body composition in former extremely low birth weight (ELBW) neonates until adulthood: a systematic review. Eur J Pediatr 179(5): 757-771.

19. Johnson MJ, Wootton SA, Leaf AA, Jackson AA (2012) Preterm birth and body composition at term equivalent age: a systematic review and metaanalysis. Pediatrics 130(3): e640-649.

20. Giannì ML, Roggero P, Piemontese P, Morlacchi L, Bracco B, et al. (2015) Boys who are born preterm show a relative lack of fat-free mass at 5 years of age compared to their peers. Acta Paediatr 104(3): e119-123.

21. Roggero P, Giannì ML, Liotto N, Taroni F, Orsi A, et al. (2011) Rapid recovery of fat mass in small for gestational age preterm infants after term. PLoS One 6(1): e14489.

22. Kiger JR, Taylor SN, Wagner CL, Finch C, Katikaneni L (2016) Preterm infant body composition cannot be accurately determined by weight and length. J Neonatal Perinatal Med 9(3): 285-290.

23. Tonkin EL, Collins CT, Miller J (2014) Protein Intake and Growth in Preterm Infants: A Systematic Review. Glob Pediatr Health 1: $2333794 X 14554698$.

24. Walsh V, Brown JVE, Askie LM, Embleton ND, Mc Guire W (2019) Nutrient-enriched formula versus standard formula for preterm infants. Cochrane Database Syst Rev 7: CD004204.

25. Hiersch L, Melamed N (2018) Fetal growth velocity and body proportion in the assessment of growth. Am J Obstet Gynecol 218(2S): S700-S711e1.

26. Raiten DJ, Steiber AL, Carlson SE, Griffin I, Anderson D, et al. (2016) Working group reports: evaluation of the evidence to support practice guidelines for nutritional care of preterm infants-the Pre-B Project. Am J Clin Nutr 103(2): 648S-678S.

27. Lapillonne A, Griffin IJ (2013) Feeding preterm infants today for later metabolic and cardiovascular outcomes. J Pediatr 162(3 Suppl): S7-16.

28. Embleton ND, Korada M, Wood CL, Pearce MS, Swamy R, et al. (2016) Catch-up growth and metabolic outcomes in adolescents born preterm. Arch Dis Child 101(11): 1026-1031.

29. Bouyssi Kobar M, Du Plessis AJ, Mc Carter R, Brossard Racine M, Murnick J, et al. (2016) Third Trimester Brain Growth in Preterm Infants Compared with In Utero Healthy Fetuses. Pediatrics 138(5): e20161640.

30. Harville EW, Buekens PM, Cafferata ML, Gilboa S, Tomasso G, et al. (2020) Measurement error, microcephaly prevalence and implications for Zika: an analysis of Uruguay perinatal data. Arch Dis Child 105(5): 428-432. 


\section{ISSN: 2574-1241}

DOI: 10.26717/BJSTR.2020.32.005314

Jacob Bornstein. Biomed J Sci \& Tech Res

(C) (i) This work is licensed under Creative Submission Link: https://biomedres.us/submit-manuscript.php

$\begin{array}{ll}\text { BIOMEDICAL } & \text { Assets of Publishing with us } \\ \text { RESEARCHES } & \text { - Global archiving of articles } \\ & \text { - Immediate, unrestricted online access } \\ & \text { - Rigorous Peer Review Process } \\ & \text { - Authors Retain Copyrights } \\ \end{array}$

